\title{
Characteristics of soil respiration temperature sensitivity in a Pinus/Betula mixed forest during periods of rising and falling temperatures under the Japanese monsoon climate
}

\author{
Yusuke Oe $^{1, *}$, Akinori Yamamoto ${ }^{2}$ and Shigeru Mariko ${ }^{3}$ \\ ${ }^{1}$ Master's Program in Life and Environmental Sciences, University of Tsukuba, Ibaraki 305-8572, Japan \\ ${ }^{2}$ Doctor's Program in Life and Environmental Sciences, University of Tsukuba, Ibaraki 305-8572, Japan \\ ${ }^{3}$ Institute of Biological Sciences, University of Tsukuba, Tsukuba 305-8572, Japan
}

\begin{abstract}
We studied temperature sensitivity characteristics of soil respiration during periods of rising and falling temperatures within a common temperature range. We measured soil respiration continuously through two periods (a period of falling temperature, from August 7, 2003 to October 13, 2003; and a period of rising temperature from May 2, 2004 to July 2, 2004) using an open-top chamber technique. A clear exponential relationship was observed between soil temperature and soil respiration rate during both periods. However, the effects of soil water content were not significant, because the humid monsoon climate prevented soil drought, which would otherwise have limited soil respiration. We analyzed temperature sensitivity using the $Q_{10}$ value and $R_{\text {ref }}$ (reference respiration at the average temperature for the observation period) and found that these values tended to be higher during the period of rising temperature than during the period of falling temperature. In the absence of an effect on soil water content, several other factors could explain this phenomenon. Here, we discuss the factors that control temperature sensitivity of soil respiration during periods of rising and falling temperature, such as root respiration, root growth, root exudates, and litter supply. We also discuss how the contribution of these factors may vary due to different growth states or due to the effects of the previous season, despite a similar temperature range.
\end{abstract}

Key words: monsoon climate, $Q_{10}$, soil respiration, temperature sensitivity

\section{INTRODUCTION}

Soil is the second largest source of atmospheric $\mathrm{CO}_{2}$, the gas produced by the respiratory activities of plant roots and microbes (Schlesinger and Andrews 2000). Knowledge of the seasonal trends in $\mathrm{CO}_{2}$ efflux from the soil (soil respiration) is important for simulating and predicting future atmospheric $\mathrm{CO}_{2}$ concentrations and the global carbon budget. Soil respiration is controlled by various environmental factors, including the temperature, moisture, and nutrient content of the soil. In the absence of drought stress, soil temperature is the most reliable predictor of soil respiration (Moncrieff and Fang 1999, Rayment and Jarvis 2000). An exponential relationship exists between soil respiration and soil temperature, as commonly described using the van't Hoff function or Arrhenius equation (Winkler et al. 1996). An increase in the reaction rate per $10^{\circ} \mathrm{C}$ increase in temperature $\left(Q_{10}\right)$ is determined using the Arrhenius equation and is used to characterize the temperature dependence of soil respira-

\section{Open Access DOI: 10.5141/JEFB.2011.021}

This is an Open Access article distributed under the terms of the Creative Commons Attribution Non-Commercial License (http://creativecommons. org/licenses/by-nc/3.0/) which permits unrestricted non-commercial use distribution, and reproduction in any medium, provided the original work is properly cited. pISSN: 1975-020X eISSN: 2093-4521
Received 03 September 2010, Accepted 09 March 2011

*Corresponding Author

E-mail: rainbow1999@gmail.com

Tel: +81-298-53-6681 
tion over a limited range of temperatures. This exponential relationship between soil temperature and soil respiration has commonly been used to estimate $\mathrm{CO}_{2}$ release from the soil on various temporal scales.

The temperature sensitivity of soil respiration has been treated as a constant in many ecosystem respiration models. However, the Arrhenius and van't Hoff assumptions of constant temperature sensitivity for respiratory enzymes at all temperatures is incorrect (Davidson and Janssens 2006). Furthermore, spatiotemporal variations in soil temperature affect the respiratory responses of autotrophs and heterotrophs. There is no doubt that simulating soil respiration without an understanding of the variation in the temperature sensitivity of soil respiration limits model utility. The use of a constant, seasonal $Q_{10}$ in models may result in significant errors in the simulation of $\mathrm{CO}_{2}$ emissions from the soil.

Some published studies have demonstrated that the $Q_{10}$ values estimated from annual data sets increase with decreasing soil temperature; e.g., approximately 2 at $30^{\circ} \mathrm{C}$ to approximately 8 at $0^{\circ} \mathrm{C}$ (Kirschbaum 1995) and 2.2 at $25^{\circ} \mathrm{C}$ to approximately 12.8 at $0.3^{\circ} \mathrm{C}$ (Lomander et al. 1998). The estimated $Q_{10}$ values incorporate not only temperature responses but also seasonal variations in soil water content (SWC), root growth phenology, and litter inputs (leaf phenology) (Curiel Yuste et al. 2004, Mo et al. 2005, Davidson and Janssens 2006). It is well known that the empirically derived $Q_{10}$ temperature function is compounded by an SWC effect, in which the SWC and soil temperature covary across seasons (Davidson et al. 1998). Fine root growth enhances specific root respiratory activity, which affects the temperature response of autotrophic respiration. Fresh litter input to the soil occurs through the incorporation of soluble substrates for microbial growth and, hence, increases heterotrophic respiration. Therefore, the seasonality of fine root growth and fresh litter inputs could account for seasonality in the $Q_{10}$ values (Curiel Yuste et al. 2005).

Reference respiration $\left(R_{\text {ref }}\right)$ is another important factor that characterizes temperature dependence models of soil respiration. $R_{\text {ref }}$ represents the magnitude of respiration at a given temperature, and, in the present study, it is used to express the average soil respiration, as it is calculated from average soil temperature. Few studies have been conducted on the seasonal variations in $Q_{10}$ and $R_{\text {ref }}$ in monsoon Asia, including Japan, where the evenly distributed annual rainfall provides a moist climate throughout the year, except for mid-summer. Japanese forests are established on volcanic ash soils, which contain considerable amounts of humus and have high water retention due to their high porosity (Ishikawa, personal communication). Cool-temperate forest soils in regions with a monsoon climate are moist throughout the year: a SWC within the range of $30-45 \%$ (not less than $20 \%$ in mid-summer in a drought year). Therefore, a seasonal variation in SWC is unlikely to compound the effects of temperature on soil respiration under these conditions.

Attempts should be made to understand the seasonal temperature sensitivity of soil respiration under a Japanese monsoon climate and determine which factor can influence temperature sensitivity. The temperature sensitivity of soil respiration can be analyzed by comparing the $Q_{10}$ and $R_{\text {ref }}$ values calculated from the data measured from spring to early summer (period of rising temperature) and from late summer to autumn (period of falling temperature) with the same temperature regime but with different biological and meteorological features. The aims of this study were to: (1) determine soil respiration and soil temperatures in a Japanese Pinus/Betula mixed forest during the abovementioned two periods, (2) analyze the seasonal changes in $Q_{10}$ values and $R_{\text {ref }}$ by approximating their data using an exponential equation, and (3) discuss how fine root growth and litterfall events as plausible factors compounded by soil temperature influence the temperature dependence of soil respiration.

\section{MATERIALS AND METHODS}

\section{Study site}

Soil respiration measurements were conducted in a $10-\mathrm{m} \times 10-\mathrm{m}$ study plot in a Pinus/Betula mixed forest at the Sugadaira Montane Research Center $\left(36^{\circ} 36^{\prime} \mathrm{N}\right.$, $138^{\circ} 21^{\prime}$ E, 1,300 m a.s.l.), University of Tsukuba, Nagano Prefecture, located in the central region of Honshu, the main island of Japan (Fig. 1). The forest is dominated by 40-year-old red pine and has developed from managed grassland dominated by Miscanthus sinensis. Tree density is approximately 1,650 trees/ha, and the mean diameter at breast height was $20.3 \mathrm{~cm}$. The ground vegetation consisted of herbs (Liliaceae spp.) and oak seedlings (Quercus crispula). The mean annual temperature over the past 30 years was $6^{\circ} \mathrm{C}$, and the region belongs to the cool-temperate zone. To analyze factors affecting soil respiration temperature sensitivity, we selected two periods characterized by a common temperature range but a different direction of temperature change: a period of rising temperature (from April to July) and a period of falling temperature (from August to October). The growing sea- 


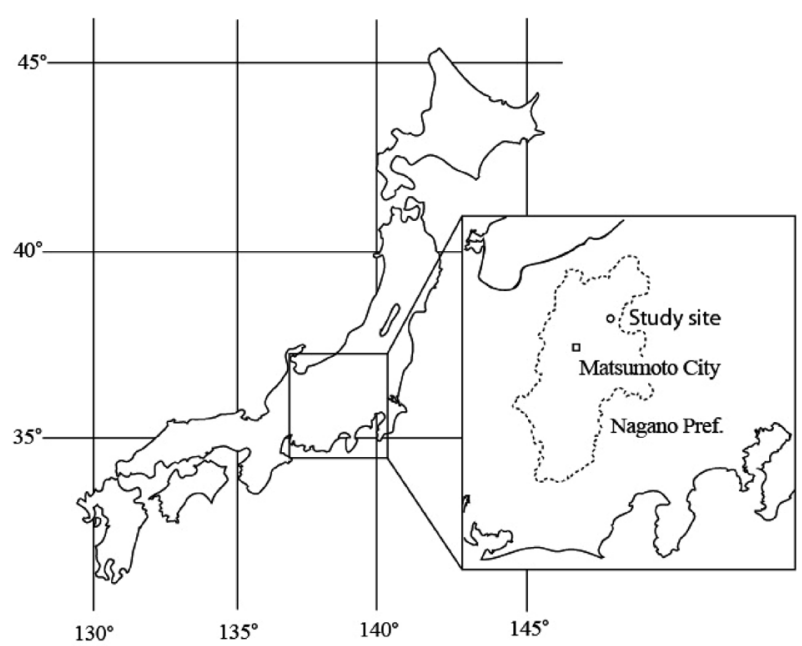

Fig. 1. Location of the study site.

son at our study site is from April to October; thus, these two periods of study represent the end and the beginning of the growing season, respectively.

The mean annual precipitation was $1,800 \mathrm{~mm}$, with two small peaks in June and September. The soil is snow covered from December to early April, with a maximum depth of more than 1-m in March.

The soil is a dark-colored, humid Andosol, and the soil profile is composed of an $\mathrm{O}$ horizon $(<3 \mathrm{~cm}$ thick), an A horizon (40-50 cm thick), and a B horizon (deeper than $50 \mathrm{~cm}$ ). The soil carbon content at $0-10 \mathrm{~cm}$ and 10 $20 \mathrm{~cm}$ was $18 \%$ and $11 \%$, respectively. The corresponding $\mathrm{C} / \mathrm{N}$ ratios were $16.5(0-10 \mathrm{~cm})$ and $17.9(10-20 \mathrm{~cm})$. Soil total porosity was approximately $87 \%$, and soil bulk density was 0.4 g/g. Soil pH measured in August 2002 was 5.0 at $0-10 \mathrm{~cm}$. The amount of carbon accumulated in the 7.6 -cm-thick litter layer was $0.15 \mathrm{~kg} / \mathrm{m}^{2}$.

\section{Soil respiration}

Soil respiration was continuously measured during the period of falling temperature from August 7, 2003 to October 13, 2003, and during the period of rising temperature from May 2, 2004 to July 2, 2004 using an opentop chamber (OTC) system. The OTC system consisted of three parts: a chamber, a sampling control unit, and a $\mathrm{CO}_{2}$ analyzer. The architecture of the chamber was the same as that developed by Fang and Moncrieff (1998) and Mariko et al. (2003). The chamber was constructed from a PVC collar, with a height of $23 \mathrm{~cm}$ (upper part, 15.5 $\mathrm{cm}$; lower part, $8.5 \mathrm{~cm}$ ) and a diameter of $16.5 \mathrm{~cm}$, and a plastic bowl with a diameter of approximately $15 \mathrm{~cm}$ designed to regulate gas flow inside the chamber. Each chamber was equipped with two lines for the uptake of sample gas and reference gas. The sample gas was collected through a thin acrylic pipe penetrating the plastic bowl, the bottom of which was exposed to the air space above the soil surface. The reference gas, which flowed from the atmosphere through the chamber-bowl space to the chamber inside, was collected by a vinyl pipe with small holes, which was installed at mid-height on the inside wall of the chamber. The sample and reference gases were continuously pumped through a vinyl tube (10-m long with a $6-\mathrm{mm}$ i.d.) to the gas sampling control unit at a rate of $1 \mathrm{~L} / \mathrm{min}$. The sampling control unit facilitated the switching of nine sets of sampling and reference lines at a constant time interval ( $4 \mathrm{~min}$ ) using a sequencer and an electric valve.

Water vapor in the pumped sampling and reference gases was removed by a deci-filter (SUNSEP-W model SEC-M04-70; Asahi Glass Engineering Co. Ltd., Chiba, Japan) before measuring the $\mathrm{CO}_{2}$ concentration using a $\mathrm{CO}_{2}$ analyzer (IRGA: BINOS 100 \& 100 4P; Rosemount Analytical, Hanau, Germany). The IRGA data were continuously logged every 20-s by a data logger (Hioki 8240; Hioki E.E. Corp., Nagano, Japan). We used the data for the last $3 \mathrm{~min}$ of a 4 -min measurement period for flux calculations using the following equation:

$$
F=(P \times M \times \Delta C \times F r \times B) /(R \times T \times A)
$$

where $F$ is the soil respiration rate $\left(\mu \mathrm{mol} \mathrm{CO}_{2} \mathrm{~m}^{-2} \mathrm{~s}^{-1}\right) ; C$, gas concentration difference between the sample and reference gasses $\left(\mathrm{m}^{3} / \mathrm{m}^{3} \times 10^{6}\right) ; A$, chamber basal area $(1 /$ $\mathrm{m}^{2}$ ); $F r$, flow rate of the sampling gas from the chamber (L/min); $R$, gas constant; $T$, air temperature; $P$, air pressure (assumed to be 0.86 ); $M$, molecular weight of $\mathrm{CO}_{2}$; $R$, gas constant; and $B$, a dimensionless constant for unit conversion.

\section{Soil temperature and soil water content}

Soil temperatures inside each chamber at 0,5 , and 10 $\mathrm{cm}$ from the surface of the A layer were monitored and logged every 20-s using a thermocouple and a data logger (Hioki 8240; Hioki E.E. Corp., Nagano, Japan) while measuring soil respiration. Moreover, the volumetric SWC at $10 \mathrm{~cm}$ from the A horizon was gravimetrically determined continuously every $30 \mathrm{~min}$ at 5 points inside the 10 -m $\times 10$-m study plot using a time domain reflectometry sensor (model EC-20; Decagon Devices Inc., Pullman, WA, USA) with two $20 \mathrm{~cm}$ long probes and a data logger (Em-5; Decagon Devices Inc.). 


\section{Litterfall}

To determine carbon input to the soil in April 2003, 16 litter traps (60 cm dia., 1-m height) were established in a lattice arrangement within a larger plot of $15-\mathrm{m} \times 15$ $\mathrm{m}$, including a plot to measure soil respiration. Litterfall was collected monthly during the growing season (MayOctober) of 2003 and weighed after drying in an oven for $24 \mathrm{~h}$ at $80^{\circ} \mathrm{C}$. Carbon content was then determined using an NC analyzer (model NC-900; Sumikca Chemical
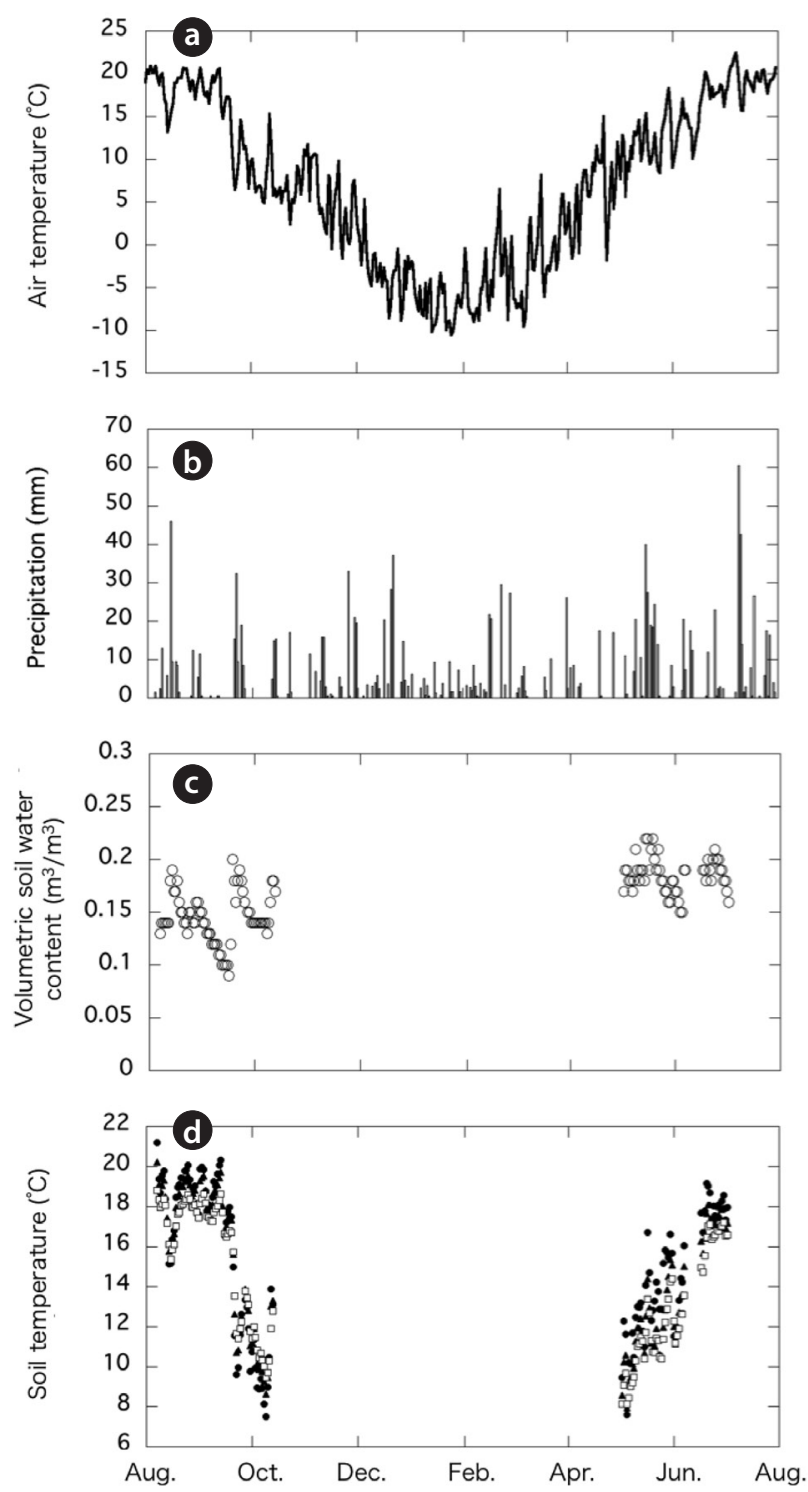

Fig. 2. Seasonal variations in daily precipitation (a), daily air temperature (b), daily mean volumetric soil water content (c), and daily mean soil temperature at $0 \mathrm{~cm}$ (white circles), $5 \mathrm{~cm}$ (black triangles), and $10 \mathrm{~cm}$ (white squares) depth (d) at the study site. Soil temperature and soil water content are shown only during the periods of falling and rising temperature (shown as hatched area).
Analysis Service Ltd., Tokyo, Japan). Litterfall during the non-growing season (November-April) was collected in April 2004.

\section{Root growth}

To clarify the effect of root growth on soil respiration, we estimated fine root production using the in-growth core method (Smit et al. 2000) at our study site. Nylon mesh bags with a mesh size of about $4 \mathrm{~mm}$ were prepared. The bags had a diameter of $5 \mathrm{~cm}$ and were about $30 \mathrm{~cm}$ long. To insert bags into the soil, a hole was drilled into the soil using a stainless steel cylinder to a depth of $30 \mathrm{~cm}$. After removing the cylinder and soil, the bags were inserted and filled with sieved soil without plant roots. On December 2005 and April 2006, mesh bags were inserted into the soil. The mesh bags were opened six times in 2006 (April, May, June, August, October, and November). Five replications were added to each bag at each opening. After collecting the mesh bags, the soil in the bags was sieved and roots were weighed after drying in an oven for 24 -h at $80^{\circ} \mathrm{C}$. We calculated net root growth rate from these results.

\section{RESULTS}

\section{Soil temperature and soil water content}

The total amount of precipitation during the study period (August 2003 to July 2004) was $1,376 \mathrm{~mm}$. The daily mean air temperature from August 2003 to July 2004 ranged from $22^{\circ} \mathrm{C}$ in July to $-10^{\circ} \mathrm{C}$ in January; the mean annual temperature was $7.0^{\circ} \mathrm{C}$ (Fig. 2a). The ranges and average air temperatures during the two periods were similar: air temperature declined from $20^{\circ} \mathrm{C}$ to $4.9^{\circ} \mathrm{C}$ during the period of falling temperature (August-October) and increased from $5.6^{\circ} \mathrm{C}$ to $20.2^{\circ} \mathrm{C}$ during the period of rising temperature (May-July). Despite the temporal difference in temperature between the two periods, the mean air temperatures during the periods of rising and falling temperature were similar: $15.1^{\circ} \mathrm{C}$ and $13.8^{\circ} \mathrm{C}$, respectively. Overall, the period of rising temperature corresponded with the start of the growing season and the period of maximum plant growth. In contrast, the period of falling temperature started when the air temperature began to fall and continued until the end of the growing season.

Soil temperature (at 0,5 , and $10 \mathrm{~cm}$ ) showed a seasonal trend similar to that of air temperature (Fig. 2d). The 

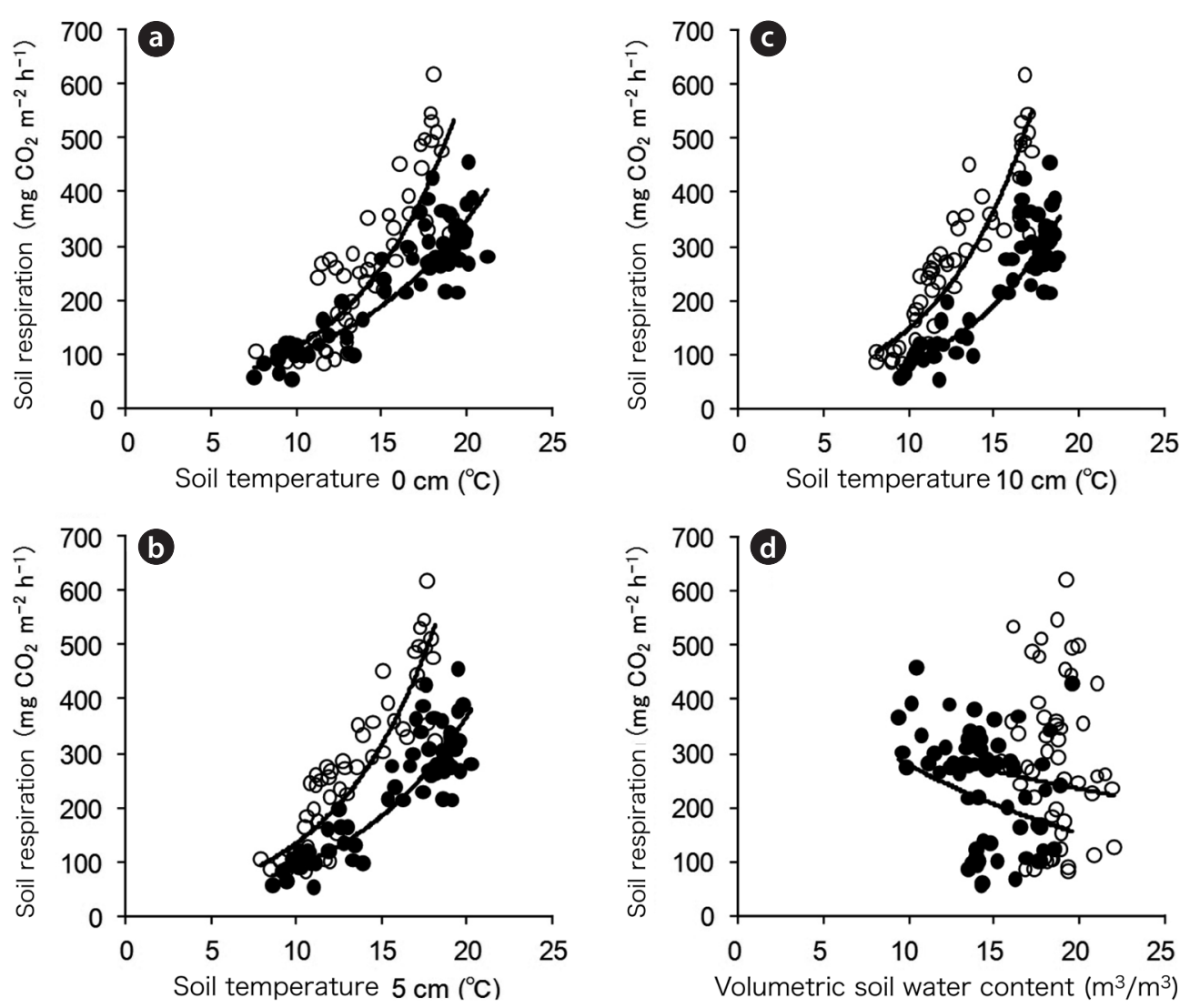

Fig. 3. Relationship between daily mean soil respiration and soil temperature (a: $0 \mathrm{~cm}, \mathrm{~b}: 5 \mathrm{~cm}$, and c: $10 \mathrm{~cm}$ ) and volumetric water content (d) during the periods of falling (black circles) and rising (white circles) temperature.

spatial variation in soil temperature was not significant at any given measurement depth among the nine chambers (data not shown). However, the temperature range ( $T_{\text {range }}$ ), the difference between $T_{\max }$ and $T_{\text {min }}$, exhibited an obvious decline with soil depth. Furthermore, $T_{\text {range }}$ at any given depth during the period of falling temperature was higher than that during the period of rising temperature. The average temperature $\left(T_{\text {ref }}\right)$ during the period of falling temperature declined with depth; however, there was no obvious trend between soil temperature and soil depth during the period.

The volumetric SWC during the periods of falling and rising temperature ranged from $9 \%$ to $20 \%$ and $15 \%$ to $22 \%$, respectively (Fig. 2b) and did not appear to exhibit temporal variation. The spatial variation of the SWC was small $(<4 \%)$.

\section{Soil respiration}

We obtained data for 67 days during the period of falling temperature and for 53 days during the period of rising temperature per chamber, with the exception of chambers 9 and 6 during the period of falling temperature due to a technical error in measurement. Soil respiration data from multiple chambers were gathered and then analyzed. The highest and lowest values of the daily mean soil respiration rate were $457 \mathrm{mg} \mathrm{CO}_{2} \mathrm{~m}^{-2} \mathrm{~h}^{-1}$ on September 13, 2003 and $53 \mathrm{mg} \mathrm{CO}_{2} \mathrm{~m}^{-2} \mathrm{~h}^{-1}$ on October 1 , 2003, respectively, during the period of falling temperature, and $620 \mathrm{mg} \mathrm{CO}_{2} \mathrm{~m}^{-2} \mathrm{~h}^{-1}$ on June 22, 2004 and $81 \mathrm{mg}$ $\mathrm{CO}_{2} \mathrm{~m}^{-2} \mathrm{~h}^{-1}$ on May 5, 2004, respectively, during the period of rising temperature.

Soil respiration was strongly correlated with soil temperatures at 0,5 , and $10 \mathrm{~cm}$ (Fig. 3a, 3b, and 3c) during both periods, which was well expressed by the following simple exponential function:

$$
\ln \mathrm{FCO}_{2}=\ln a+b \times T_{\mathrm{s}}
$$

where $\mathrm{FCO}_{2}$ is the $\mathrm{CO}_{2}$ emission rate $\left(\mu \mathrm{mol} \mathrm{CO} \mathrm{Cm}^{-2} \mathrm{~s}^{-1}\right)$, $a$ and $b$ are constants, and $T_{\mathrm{s}}$ is the soil temperature $\left({ }^{\circ} \mathrm{C}\right)$. The correlation coefficient $\left(r^{2}\right)$ between the temperature 
and daily soil respiration was high (min., 0.73; max., 0.84) and varied slightly with depth, such that the measured soil temperatures were in the order $0 \mathrm{~cm}<5 \mathrm{~cm}<10 \mathrm{~cm}$ during the period of falling temperature and $10 \mathrm{~cm}<5$ $\mathrm{cm}<0 \mathrm{~cm}$ during the period of rising temperature (Table 1). The magnitude of soil respiration during the period of rising temperature was higher at any given observed temperature than that during the period of falling temperature $(P<0.05)$.

From Eq. 2, the $Q_{10}$ (temperature coefficient) can be calculated as follows:

$$
Q_{10}=\exp (10 \times b)
$$

We define $R_{\text {ref }}$ based on $T_{\text {ref }}$ as follows:

$$
R_{\text {ref }}=a \times \exp \left(b \times T_{\text {ref }}\right)
$$

Table 1 shows the $R_{\text {ref }}$ and $Q_{10}$ values calculated from all the soil respiration data for chambers 9 or 6 . These parameters showed different trends during the two study periods and varied with soil depth. The $R_{\text {ref }}$ value, the soil respiration rate at $T_{\text {ref }}$ during the period of rising temperature was greater than that during the period of falling temperature at any given soil depth $(P<0.05)$, although it did not show an obvious trend with soil depth. During the period of rising temperature, soil temperature at any depth was greater than the $Q_{10}$ value during the period of falling temperature $(P<0.05)$. In both periods, all data sets exhibited an increase in the $Q_{10}$ value with depth. However, no significant relationship was found between soil respiration and SWC during either period (Fig. 3d).

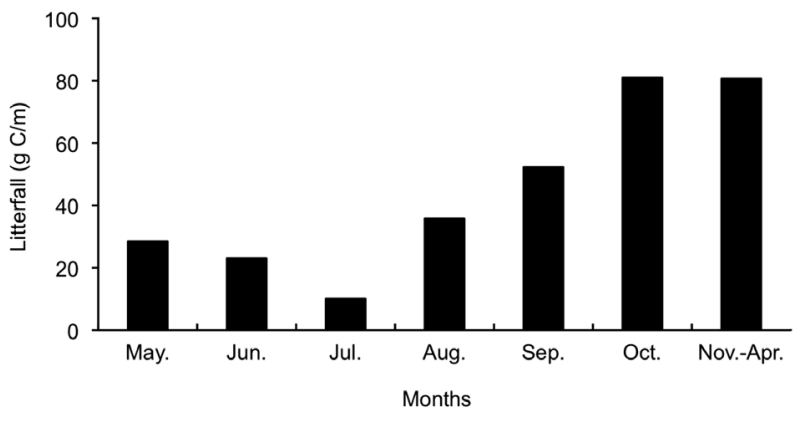

Fig. 4. Seasonal variation in litterfall measured at 16 points in 2003.

\section{Litterfall}

Fig. 4 shows the seasonal variation in litterfall during 2003 to 2004. A large peak was observed in September and October, and the spatial variation was small. We estimated soil carbon input from litterfall assuming that the carbon content of litterfall was $50 \%$. There was approximately $30 \mathrm{~g} \mathrm{C}$ d.w. $/ \mathrm{m}^{2}$ and $85 \mathrm{~g} \mathrm{C}$ d.w. $/ \mathrm{m}^{2}$ during the periods of falling and rising temperature, respectively. The amount of litterfall in the period of falling temperature was twice that in the period of rising temperature and was mostly observed during the last month of measurements.

\section{Root growth}

Fig. 5 shows the estimated net root growth rate $(N=$ 5) using the ingrowth core method. Net root growth of fine roots started in May, peaked in June and July then declined from August to November. The estimated net root growth rate of coarse roots also started in May and

\begin{tabular}{|c|c|c|c|c|c|c|c|}
\hline Soil depth (cm) & $T_{\max }\left({ }^{\circ} \mathrm{C}\right)$ & $T_{\min }\left({ }^{\circ} \mathrm{C}\right)$ & $T_{\text {range }}\left({ }^{\circ} \mathrm{C}\right)$ & $T_{\text {ref }}\left({ }^{\circ} \mathrm{C}\right)$ & $R_{\text {ref }}$ & $r^{2}$ & $Q_{10}$ \\
\hline \multicolumn{8}{|l|}{ Falling } \\
\hline 0 & 20.31 & 7.52 & 12.79 & 13.91 & 161.77 & 0.84 & 3.32 \\
\hline 5 & 19.71 & 8.59 & 11.12 & 14.15 & 168.49 & 0.83 & 4.06 \\
\hline 10 & 18.62 & 8.14 & 10.48 & 13.38 & 145.62 & 0.82 & 4.95 \\
\hline \multicolumn{8}{|l|}{ Rising } \\
\hline 0 & 19.16 & 7.61 & 11.55 & 13.39 & 200.44 & 0.73 & 5.47 \\
\hline 5 & 18.09 & 7.95 & 10.14 & 13.02 & 226.40 & 0.75 & 5.47 \\
\hline 10 & 17.21 & 8.14 & 9.07 & 12.68 & 226.99 & 0.79 & 6.05 \\
\hline
\end{tabular}

Table 1. The exponential relationship (Eq. 1) between daily mean soil respiration and soil temperature

$T_{\max ,}$ maximum temperature; $T_{\min }$, minimum temperature; $T_{\text {range, }}$ difference between $T_{\max }$ and $T_{\min } ; T_{\text {ref, }}$ median soil temperature for the period; $r^{2}$, correlation coefficient between soil temperature and soil respiration; $Q_{10}, Q_{10}$ value of the temperature-respiration relationship. 


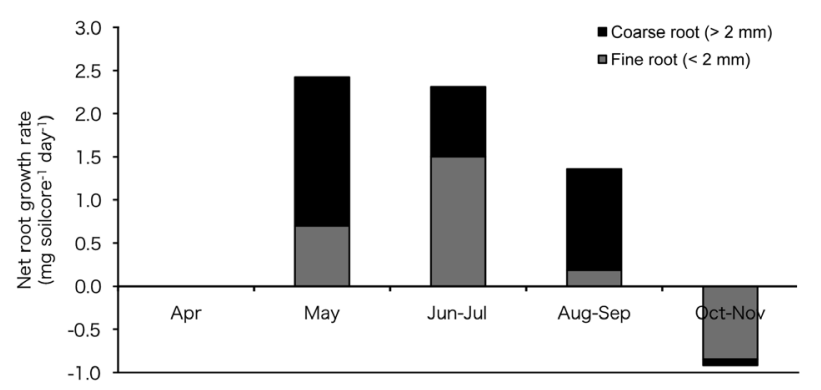

Fig. 5. Seasonal variation in net root growth rate (black:coarse, root gray:fine root) using the ingrowth core method in 2006.

declined in June and July; however, it increased again in August to September and was almost absent in October and November. Total net root growth rate (fine root growth + coarse root growth) was not observed in April and appeared in May but declined sharply in summer and autumn.

\section{DISCUSSION}

\section{Influence of SWC on the temperature dependence of soil respiration}

Similar to our results, many other researchers have found that the $Q_{10}$ exhibits seasonal variation. In some studies, $Q_{10}$ exhibited a negative relationship with temperature, with low $Q_{10}$ values observed during the hightemperature season (Xu and Qi 2001, Janssens and Pilegaard 2003, Almagro et al. 2009, Chen et al. 2010). These authors reported declines in decomposition activity during the high-temperature period as a consequence of soil drought. However, we observed no decline in SWC during the high-temperature period because of plentiful rainfall and the high-water retention of the forest soil, which coincided with the end of the period of rising temperature and the beginning of the period of falling temperature, indicating that soil respiration was not restricted by SWC during this season. Therefore, our observation that $Q_{10}$ during the period of rising temperature was higher than that during the period of falling temperature (Table 1) should be explained not by the SWC but by other factors.

Other researchers have suggested that the phenology of the above-ground plant parts or the balance of litter supply are factors controlling the seasonal fluctuation in the temperature sensitivity of soil respiration (Curiel Yuste et al. 2004, Mo et al. 2005, Davidson and Janssens 2006). However, at their study sites, the significant effects of SWC on soil respiration obscured the effects of other potential factors. In contrast, the lack of drought during the growing season at our site made it easier to assess other factors that might affect the sensitivity of soil respiration.

\section{The effect of artificial observations}

Several factors may explain the hysteresis of $Q_{10}$ and $R_{\text {ref }}$ that was observed in the seasonal difference between soil temperature and soil respiration at our study site (Fig. 3). First, we should consider the artificial effect of the chosen depths at which the soil temperatures were used to calculate the $Q_{10}$ value and $R_{\text {ref }}$. Some researchers (Swanson and Flanagan 2001, Oe and Mariko 2005) have indicated that the $Q_{10}$ value increases with soil depth at which the temperature is observed, because the range of temperature fluctuation ( $T_{\text {range }}$ ) decreases with depth. Essentially, $Q_{10}$ and $R_{\text {ref }}$ must be calculated at depths where soil respiration is most active. However, because it is difficult to determine this depth, soil temperature is generally measured at depths where the highest $r^{2}$ value in the temperature-respiration $(T-R)$ relationship is obtained. Our $r^{2}$ values for the depths of 0,5 , and $10 \mathrm{~cm}$ were very high (>0.7) and were similar during the periods of falling and rising temperature, indicating the minimal effect of artificial observation in this study. This allowed us to compare $Q_{10}$ values calculated at the same depth during the two periods.

$R_{\text {ref }}$ should also be calculated from a soil depth with a high $r^{2}$ value for the $T$ - $R$ curve, because $R_{\text {ref }}$ represents respiration at the average soil temperature estimated from the $T$ - $R$ curve. Thus, the $R_{\text {ref }}$ values obtained from the same depth as those for $Q_{10}$ are discussed in this study.

\section{The effect of root phenology}

Root respiration represents a considerable fraction of soil respiration in temperate forests (Hanson et al. 2000), and the effect of root respiration on the temperature sensitivity of soil respiration is quite large. Root respiration comprises growth respiration, which is proportional to root growth rate and maintenance respiration, which is proportional to root biomass, and these two respiratory processes differ in their effect on $R_{\text {ref }}$ and $Q_{10} . R_{\text {ref }}$ depends on both types of respiration, whereas $Q_{10}$ is influenced only by maintenance respiration, as respiration for growth is not temperature dependent (Johnson and Thornley 1985). Thus, it is important to discuss the seasonal dynamics of these two components to analyze 
the temperature sensitivity of soil respiration. In this study, we did not determine the seasonal dynamics of root biomass and respiration activity of roots. However, Noguchi et al. (2005) reported seasonal variation in fine root length, production, and mortality in Japanese cedar forests using the mini rhizotron technique. At their site, there was also an absence of summer drought and the climate was similar to that of our study site; consequently, root phenology of the two sites was also probably similar. Noguchi et al. (2005) found a small peak in fine root biomass in the upper soil layer $(0-20 \mathrm{~cm})$ in summer $(24$ May to 21 August); however, the seasonal changes in fine root lengths were not significant. This suggests that the effect of maintenance respiration on $R_{\text {ref }}$ and $Q_{10}$ in Japanese conifer forests is small.

Seasonal variations in root growth respiration can be presumed from our results of seasonal net root growth rate using the ingrowth core (Fig. 5), which was high during the rising temperature period (May to July) and low during the falling temperature period (August to October). This result suggests greater growth respiration activity during the period of rising temperature than that during the period of falling temperature, and this could be one of the factors contributing to the high $R_{\text {ref }}$ observed during the period of rising temperature. Noguchi et al. (2005) also reported a peak in root production during summer (May 24 to August 21), corresponding to the period of rising temperature, similar to our site.

Heterotroph respiration in the rhizosphere is strongly influenced by root mortality and the supply of exudation substrate. At the beginning of the period of rising temperature, large amounts of photosynthesis are allocated to below-ground plant parts in response to rapid growth and may be supplied as root exudates. Root exudates mainly comprise readily decomposable substances such as organic acid anions, phytosiderophores, sugars, vitamins, and amino acids (Dakora and Phillips 2002), and the exudation process contributed to a high $R_{\text {ref }}$ during the period of rising temperature. During the period of falling temperature, when the allocation of photosynthates to the roots decreases, the amount of root exudates was also reduced, which resulted in a lower $R_{\text {ref }}$ A portion of the substrates supplied during the period of rising temperature persisted until the period of falling temperature and may have affected soil respiration during the latter period. In an incubation experiment, Winkler et al. (1996) demonstrated that heterotrophic respiration decreases after a high-temperature period due to the lack of readily decomposable substrates. Instead of substrates supplied by exudates during the period of falling temperature, the increase in dead fine roots toward the end of the growing season would enhance heterotrophic respiration. However, the lower decomposability of dead roots compared to root substrates and the low temperature at the end of the period of falling temperature may have inhibited the enhanced heterotrophic respiration sufficiently to affect the temperature dependence of soil respiration.

\section{The effect of litterfall}

Generally, the seasonal variation in heterotrophic respiration is influenced, in part, by the timing of litterfall, which serves as a substrate for microbial decomposition. For example, Curiel Yuste et al. (2005) reported that autumn litterfall was followed by a rapid increase in soil respiration despite decreasing soil temperature in temperate oak forests. If an accelerating effect of fresh litter on soil respiration had occurred in our Pinus/Betula mixed forest, rich litterfall in September and October (Fig. 4) it would have influenced the temperature dependence of soil respiration during the period of falling temperature. It is probable that soil respiration does not decrease with decreasing soil temperature toward late autumn, or only slightly decreases. As a result, $Q_{10}$ during the period of falling temperature may be smaller than that during the period of rising temperature.

In the study of Curiel Yuste et al. (2005), newly supplied "oak litter" would have enhanced soil microbe respiratory activity. However, the accelerating effect of fresh litter on soil respiration may be caused by the high decomposability of oak litter. The dead needle leaves of conifers, which have a higher content of lignin than the leaves of broadleaf trees, have low decomposability (Osono and Takeda 2005). Moreover, because the temperature was low when litterfall occurred and the soil was covered by snow, the effect of decomposing fresh "conifer-mixed" litterfall during the period of falling temperature could be small.

\section{CONCLUSION}

We suggest that root phenology and litterfall are the two main factors contributing to the difference in soil respiration characteristics, particularly temperature dependence and the magnitude of soil respiration between periods of rising and falling temperature. Biological factors such as root phenology and the quality and temporal availability of substrates are key parameters that characterize the seasonality of soil respiration in Asian mon- 
soon forests, which typically experience humid summers and large temperature fluctuations. We found an apparent seasonal change in the characteristics of soil respiration in a Pinus/Betula mixed forest. However, the forest floor is generally covered by vegetation in broadleaf forests in temperate monsoon Asia. The effect of this vegetation on soil carbon dynamics is quite large and its effect on soil respiration may be more complicated. However, we were unable to quantify the effects of root exudation and microbial activity on soil respiration. Moreover, it is generally acknowledged that soil respiration varies during the year in temperate forest ecosystems (Phillips et al. 2010), which we did not observe in this study. Hence, in future investigations we will need to directly survey these factors in field observations for at least 2 years and conduct laboratory experiments to reveal the biochemical characteristics of soil respiration.

\section{ACKNOWLEDGMENTS}

We thank Professors I. Hayashi and T. Oikawa, University of Tsukuba, for their encouragement and support during the study period. We also acknowledge the members of the Terrestrial Ecosystem Laboratory, University of Tsukuba, for their help. This study was performed as part of the "GCMAPS program" (Global Carbon Cycle and Related Mapping Based on Satellite Imagery) sponsored by the Ministry of Education, Culture, Sports, Science and Technology of Japan.

\section{LITERATURE CITED}

Almagro M, López J, Querejeta JI, Martínez-Mena M. 2009. Temperature dependence of soil $\mathrm{CO}_{2}$ efflux is strongly modulated by seasonal patterns of moisture availability in a Mediterranean ecosystem. Soil Biol Biochem 41: 594-605.

Chen B, Liu S, Ge J, Chu J. 2010. Annual and seasonal variations of $Q_{10}$ soil respiration in the sub-alpine forests of the Eastern Qinghai-Tibet Plateau, China. Soil Biol Biochem 42: 1735-1742.

Curiel Yuste J, Janssens IA, Carrara A, Ceulemans R. 2004. Annual $Q_{10}$ of soil respiration reflects plant phenological patterns as well as temperature sensitivity. Glob Change Biol 10: 161-169.

Curiel Yuste J, Janssens IA, Ceulemans R. 2005. Calibration and validation of an empirical approach to model soil $\mathrm{CO}_{2}$ efflux in a deciduous forest. Biogeochemistry 73:
209-230.

Dakora FD, Phillips DA. 2002. Root exudates as mediators of mineral acquisition in low-nutrient environments. Plant Soil 245: 35-47.

Davidson EA, Belk E, Boone RD. 1998. Soil water content and temperature as independent or confounded factors controlling soil respiration in a temperate mixed hardwood forest. Glob Change Biol 4: 217-227.

Davidson EA, Janssens IA. 2006. Temperature sensitivity of soil carbon decomposition and feedbacks to climate change. Nature 440: 165-173.

Fang C, Moncrieff JB. 1998. An open-top chamber for measuring soil respiration and the influence of pressure difference on $\mathrm{CO}_{2}$ efflux measurement. Funct Ecol 12: 319-325.

Hanson PJ, Edwards NT, Garten CT, Andrews JA. 2000. Separating root and soil microbial contributions to soil respiration: a review of methods and observations. Biogeochemistry 48: 115-146.

Janssens IA, Pilegaard K. 2003. Large seasonal changes in $Q_{10}$ of soil respiration in a beech forest. Glob Change Biol 9: 911-918.

Johnson IR, Thornley JHM. 1985. Temperature dependence of plant and crop processes. Ann Bot 55: 1-24.

Kirschbaum MUF. 1995. The temperature dependence of soil organic matter decomposition, and the effect of global warming on soil organic C storage. Soil Biol Biochem 27: 753-760.

Lomander A, Kätterer T, Andrén O. 1998. Modelling the effects of temperature and moisture on $\mathrm{CO}_{2}$ evolution from top- and subsoil using a multi-compartment approach. Soil Biol Biochem 30: 2023-2030.

Mariko S, Kibe T, Sekikawa S, Hirota M, Kinoshita N, Mochiduki K, Oikawa T. 2003. In situ measurement of soil respiration using the open-top chamber technique. J Jpn Agric Syst Soc 19: 160-165.

Mo W, Lee MS, Uchida M, Inatomi M, Saigusa N, Mariko S, Koizumi H. 2005. Seasonal and annual variations in soil respiration in a cool-temperate deciduous broad-leaved forest in Japan. Agric For Meteorol 134: 81-94.

Moncrieff JB, Fang C. 1999. A model for soil $\mathrm{CO}_{2}$ production and transport: 2. application to a Florida Pinus elliotte plantation. Agric For Meteorol 95: 237-256.

Noguchi K, Sakata T, Mizoguchi T, Takahashi M. 2005. Estimating the production and mortality of fine roots in a Japanese cedar (Cryptomeria japonica D. Don) plantation using a minirhizotron technique. J For Res 10: 435441.

Oe Y, Mariko S. 2005. Seasonal variation in $\mathrm{CH}_{4}$ uptake and $\mathrm{CO}_{2}$ emission in Japanese temperate deciduous forest 
soil. In: Global Climate Change and Response of Carbon Cycle in the Equatorial Pacific and Indian Oceans and Adjacent Landmasses, Vol. 73 (Kawahata H, Awaya Y, eds). Elsevier, Amsterdam, pp 445-463.

Osono T, Takeda H. 2005. Decomposition of organic chemical components in relation to nitrogen dynamics in leaf litter of 14 tree species in a cool temperate forest. Ecol Res 20: 41-49.

Plillips SC, Varner RK, Frolking S, Munger JW, Bubier JL, Wofsy SC, Crill PM. 2010. Interannual, seasonal, and diel variation in soil respiration relative to ecosystem respiration at a wetland to upland slope at Harvard Forest. J Geophys Res 115: G02019.

Rayment MB, Jarvis PG. 2000. Temporal and spatial variation of soil $\mathrm{CO}_{2}$ efflux in a Canadian boreal forest. Soil Biol Biochem 32: 35-45.
Schlesinger W, Andrews J. 2000. Soil respiration and the global carbon cycle. Biogeochem 48:7-20.

Smit AL, Bengough AG, Engels C, van Noordwijk M, Pellerin S, van de Geijn SC. 2000. Root Methods: A Handbook. Springer-Verlag, Berlin, pp 175-210.

Swanson RV, Flanagan LB. 2001. Environmental regulation of carbon dioxide exchange at the forest floor in a boreal black spruce ecosystem. Agric For Meteorol 108: 165181.

Winkler JP, Cherry RS, Schlesinger WH. 1996. The $Q_{10}$ relationship of microbial respiration in a temperate forest soil. Soil Biol Biochem 28: 1067-1072.

Xu M, Qi Y. 2001. Spatial and seasonal variations of $Q_{10}$ determined by soil respiration measurements at a Sierra Nevadan forest. Glob Biogeochem Cycles 15: 687-696. 